Commission IV.1 on Macromolecular Nomenclature was formed. "All other work was done by Working Groups, ad hoc Committees, and individual experts."1

Following the initial macromolecular emphasis, Commission IV.2 on Polymer Characterization and Properties was formed in 1975. Gradually, over the years, Division IV's work has expanded away from individual macromolecules towards polymers as substances and materials. However, the molecular areas of activity still retain their importance.

Under the present, project-based operating system of IUPAC, Division IV has structured itself to cover the following areas of activity, each organized by one, two, or three coordinators:

- Structure-Property Characterization of Commercial Polymers

- Modeling of Polymerization Kinetics and Processes

- Macromolecular Terminology

- Macromolecular Nomenclature (in collaboration with Division VIII)

- Molecular Characterization of Polymers

- Developing Polymer Materials Systems

- Polymer Education

Of these areas, only Macromolecular Nomenclature and Molecular Characterization of Polymers deals with individual macromolecules. Division IV's concerns are now much broader than when it was formed 37 years ago. In general terms, the division's present work deals with macromolecules, polymer substances and materials, and polymer-based materials. Hence, the members of Division IV have chosen to rename it "Polymer Division." The name is simple and straightforward, and adequately describes Division IV's activities, now and into the foreseeable future.

www.iupac.org/divisions/IV

\section{Young Chemists to the 40th IUPAC Congress}

he 40th IUPAC Congress will be held 14-19 August 2005 in Beijing, China, on the theme "Innovation in Chemistry." To encourage young chemists to participate in this unique congress, the organizers have established two different programs, both offering travel assistance. The first program is especially targeted to young scientists from develop- ing and economically disadvantaged countries; the second is open to chemists from any country. For each program respectively, about 30 and 20 awards of up to USD 1500 will be made available to qualified candidates to cover some or all of their Congress registration fees and/or some or all of their travel expenses.

Applications from candidates under age 40 are welcomed. Applications may be submitted directly to the address below. There is no specific application form, but applicants are required to provide:

- a letter of application

- a brief CV

- a confirmation of their current status and affiliation

- a publication list

- a letter of support from the appropriate department head, dean, or laboratory supervisor

- an abstract of the poster or paper to be presented at the Congress

- estimates of the economy airfare to and from the Congress

The deadline for receipt of applications is $\mathbf{2 8}$ February 2005. Award of travel support will automatically include acceptance of a candidate's abstract. As all abstracts are subject to adjudication, those candidates whose applications for travel support are unsuccessful could still have their abstracts accepted. All applicants will be notified of the outcome by 15 March 2005.

Applications should be sent to:

Prof. Xibai QIU

Secretary, IUPAC-05

c/o Chinese Chemical Society

No 2, Beiyijie St., Zhongguancun

Beijing 100080, China

E-mail: qiuxb@iccas.ac.cn

Fax/Tel: +86-10-62568157

$<$ www.iupac-congress05.org.cn>

<www.ccs.ac.cn/IUPAC2005.htm>

Note: This opportunity for young chemists to participate in the 40th Congress is independent of the Young Observers program (described in the Nov-Dec 2004 Cl), which is coordinated by the USA, UK, and IUPAC Secretariat. 